\title{
EI discurso en los proyectos culturales de la música latinoamericana: de la nueva canción a la canción social en Colombia ${ }^{1}$
}

\author{
Joshua Katz-Rosene \\ https://orcid.org/0000-0002-9085-4354 \\ Franklin \& Marshall College \\ joshkr@fandm.edu
}

\section{Daniel Castelblanco (trad.)}

(iD) https://orcid.org/0000-0003-1704-3616

Elon University

dcastelblanco@elon.edu,dac98@georgetown.edu

\section{PRESENTACIÓN}

A la memoria de Roger Díaz, impulsor clave de la música latinoamericana en la ciudad de Medellin, fundador del Grupo Illary e interlocutor indispensable en esta investigación, quien falleció en abril de 20212.

Mediante un proceso que reemplazó su previa identidad andina por una tropical, durante la segunda mitad del siglo XX la nación colombiana proyectó una variedad de expresiones musicales populares indexales de la región Caribe que incluyen el vallenato y, por supuesto, la cumbia. Desde entonces, el interés académico sobre la música en Colombia ha oscilado entre el estudio del folclor regional indígena y campesino, la música popular comercial y, en años recientes, la denominada «nueva música colombiana».

Traducción del artículo Discourse in música latinoamericana Cultural Projects from nueva canción to Colombian canción social, publicado en Volume!, 11(2), 65-83, 2015.

2 Una breve semblanza de Roger se encuentra disponible en el enlace a continuación: https:// www.elcolombiano.com/cultura/musica/vocalista-y-creador-del-grupo-illary-roger-diazmurio-por-covid-EK14962363 
En lo relativo a la recepción que han tenido estilos musicales internacionales entre las audiencias colombianas, la atención académica se ha enfocado en géneros como el bolero, el tango, la ranchera y la salsa, así como en diversas tendencias del rock. Pero en contraste con la consideración que la academia ha brindado a la nueva canción latinoamericana y sus proyectos culturales en otros países, en Colombia la crítica más bien ha soslayado su impacto. Este artículo del etnomusicólogo canadiense Joshua Katz-Rosene, publicado originalmente en inglés en 2015, salda por fin esta deuda impostergable.

Sobre la base de entrevistas, un riguroso trabajo de campo y el escrutinio de diversos archivos en diferentes ciudades de los Andes colombianos, Katz-Rosene examina los discursos relativos a la denominada «música latinoamericana» para iluminar la compleja relación entre música y la política durante la segunda mitad del siglo XX y el inicio del XXI en Colombia. En particular, el autor examina los originales discursos mediante los que una cohorte de músicos comprometidos justificó su adopción de variantes musicales emparentadas con el movimiento de la «nueva canción latinoamericana» desde la década de 1970. Siguiendo el modelo formulado por el sociólogo estadounidense William Roy para entender la politización de estilos musicales folclóricos, Katz-Rosene traza el surgimiento, desarrollo y uso contemporáneo del abanico de categorías musicales con que los músicos locales identifican los géneros y estilos que interpretan. En efecto, en Colombia suelen emplearse categorías como «música andina», «música latinoamericana», «canción protesta» y «canción social» como si se tratara de sinónimos intercambiables. Una de las contribuciones clave que ofrece este trabajo consiste en aclarar, de una vez por todas, la confusión terminológica que ha comprometido la profundidad del debate académico en torno al papel de estas expresiones musicales en Colombia.

En momentos en que la denuncia social se encuentra en la voz de otras expresiones musicales, como el rap, la traducción de este valioso artículo busca contribuir a la comprensión sobre las relaciones entre formas culturales y activismo político en el contexto de desigualdad social y violencia que ha marcado el tránsito de Colombia hacia el XXI.

Daniel Castelblanco Wake Forest University dac98@georgetown.edu 
RESUMEN

En este artículo rastreo los discursos que circundan la denominada «música latinoamericana», una categoría musical bastante amplia que reúne diversos géneros folclóricos latinoamericanos, especialmente andinos, y que se encuentra inscrita en «proyectos culturales» sucesivos e interrelacionados. Examino los significados extramusicales que movimientos contestatarios como la nueva canción, en el Cono Sur, y la red transnacional de la nueva canción latinoamericana atribuyeron a este estilo musical, para luego enfocarme en el desarrollo que tuvo la música latinoamericana en Colombia. A mediados de la década de 1970, los primeros intérpretes colombianos de música latinoamericana adoptaron numerosas facetas del discurso relacionado con la nueva canción latinoamericana, incluyendo sus modelos musicales. Sin embargo, no tardaron en refinar sus argumentos acerca del significado del estilo, su peculiaridad frente a otros géneros musicales y su simbolismo politico, con el propósito de adaptarlos a los cambiantes contextos culturales de las ciudades colombianas del interior. Sostengo que el «trabajo» discursivo que asumieron estos proyectos culturales ha conseguido que, en Colombia, la música latinoamericana siga siendo equiparada a tendencias políticas contestatarias y que, por tanto, se mantenga estrechamente vinculada a la "canción social», la categoría vigente para la música socialmente comprometida.

Palabras clave: Colombia, música de protesta, nueva canción, política, proyectos culturales.

\title{
Discourse in Música Latinoamericana Cultural Projects from Nueva Canción to Colombian Canción Social
}

\author{
ABSTRACT
}

In this article, I follow the discourses elaborated around música latinoamericana ("Latin American music»), a broad musical category encompassing a wide range of Latin American - but especially Andean-folk genres within successive, interrelated "cultural projects». I examine the extra-musical meanings attributed to this 
stylistic mode in the nueva canción (new song) movements of protest music in the Southern Cone, the transnational nueva canción latinoamericana (Latin American New Song) network to which they gave rise, and ultimately focus on música latinoamericana's development in Colombia. During the mid 1970s, the initial Colombian practitioners of música latinoamericana adopted several facets of the discourse pertaining to this music — along with the musical models themselves - from nueva canción latinoamericana. However, they later reined claims about the style's significance, its distinctiveness from other musical genres, and its political symbolism to fit changing cultural contexts in the cities of the Colombian interior. I argue that the discursive «work» undertaken in these cultural projects has ensured that música latinoamericana continues to be equated with anti-establishment politics in Colombia, and hence that it remains closely tied to canción social («social song»), the present-day category for socially conscious music.

Keywords: Colombia, cultural projects, nueva canción, politics, protest music. 
En la historia reciente, movimientos e instituciones tanto de carácter progresista como conservador, en posiciones subordinadas así como hegemónicas, comprometidas con la protesta o involucradas con el control totalitario, se han apoyado en recursos culturales etiquetados como folclóricos para promover sus objetivos políticos. Desde la perspectiva norteamericana, uno de los casos mejor documentados de este fenómeno es la apropiación de la música folclórica del sur de los Estados Unidos durante la era del Frente Popular por parte de activistas del Partido Comunista americano, en la década de 1930, y su posterior integración a la cultura izquierdista norteamericana a mediados del siglo XX. Movimientos distintos pueden tener motivaciones divergentes $\mathrm{y}$, asimismo, diversas formas de inscribir la música folclórica en sus respectivas causas. No obstante, todos ellos deben lidiar con los discursos preexistentes relacionados con el concepto de «folclor» y enmarcar las ideas que emanan de estos discursos de modo que se ajusten a sus propias ideologías. William Roy ha propuesto que las categorías musicales basadas en el folclor son socialmente construidas y que, en algunos casos, son politizadas mediante el «trabajo» discursivo que se desarrolla dentro de diversos «proyectos culturales» (2010, pp. 50-51).

En este artículo rastreo el desarrollo de los discursos que circundan la «música latinoamericana», una categoría musical bastante amplia que reúne diversos géneros folclóricos latinoamericanos, especialmente andinos, y que se encuentra inscrita en proyectos culturales sucesivos e interrelacionados. Empiezo con los movimientos de música protesta de la nueva canción en el Cono Sur, y continúo con la red transnacional de la nueva canción latinoamericana a la que estas dieron origen, para enfocarme luego en el desarrollo que tuvo la música latinoamericana en Colombia. A mediados de la década de 1970, los primeros intérpretes de música latinoamericana en Colombia adoptaron numerosas facetas del discurso relacionado con la nueva canción latinoamericana (en adelante NCL), incluyendo sus modelos musicales. Sin embargo, no tardaron en refinar sus argumentos acerca del significado del estilo, su peculiaridad frente a otros géneros musicales y su simbolismo político, con el propósito de adaptarlos a los 
cambiantes contextos culturales de las ciudades colombianas del interior. Sostengo que el marco conceptual que produjeron, en conjunción con estos proyectos culturales, ha asegurado que, en Colombia, la música latinoamericana siga siendo equiparada a tendencias políticas contestatarias.

A partir de mediados de la década de 1960, conjuntos chilenos de la nueva canción, como Quilapayún e Inti-Illimani, adoptaron un formato musical en el que sobresalían instrumentos andinos como la quena, la zampoña, el charango y el bombo, y conformaron repertorios que otorgaban un lugar destacado a arreglos estilizados de géneros rurales, mestizos e indígenas de Perú (huayno), Bolivia (huayño, cueca), el noroeste argentino (bailecito, carnavalito, zamba) y, en menor medida, Ecuador (sanjuanito). No obstante, estos conjuntos también interpretaban géneros folclóricos de lugares tan variados como Cuba (son), Venezuela (joropo), México (son) y Chile mismo (cueca, trote y cachimbo), e incorporaron muchos de los instrumentos tradicionalmente empleados en su ejecución ${ }^{3}$. Estas agrupaciones florecieron hacia finales de la década de 1960, en sincronía con la campaña política que llevó la coalición socialista de la Unidad Popular al poder en Chile en 1970. Tras el golpe de estado liderado por Augusto Pinochet en 1973, la mayoría de los artistas de la nueva canción fueron forzados al exilio y muchos pasaron años viajando por el mundo invocando la solidaridad internacional con la lucha del pueblo chileno por restaurar la democracia.

Desde finales de la década de 1960, la nueva canción chilena impactó de manera profunda a los artistas con inclinaciones políticas de izquierda a lo largo y ancho de Latinoamérica (Gómez, 1973). En el radar de los músicos colombianos también se encontraban el nuevo cancionero argentino, inaugurado por músicos e intelectuales argentinos en 1963, así como la variante uruguaya de música protesta conocida como canto popular. Durante este periodo, la conjunción de la nueva trova cubana y sus movimientos homólogos en el Cono Sur empezaron a dar forma a la escena internacional de la NCL, cuya influencia crecía cada vez más. La forma que encontraron los músicos colombianos para hacer música de oposición se vino a conocer a partir de la década de 1960 como «canción protesta». En 1968 un pequeño grupo de músicos en Bogotá fundó el Centro Nacional de Canción Protesta. Durante algunos años este albergó una peña de música folclórica y de protesta en el tradicional barrio La Candelaria ("Canciones de protesta y esperanza”, 1968; Gómez, 1973). Entre los artistas que participaban en este

3 El disco de Inti-Illimani Cóndores del Sol, publicado en 1970, ofrece un buen ejemplo de este enfoque (ver figura 1). 


\begin{tabular}{|l|l|l|}
\hline Track & Genre & Country \\
\hline 1. Los Arados & Sanjuanito & Ecuador \\
3. Nuestro México, Febrero 23 & corrido & Argentina \\
4. Dolencias & triste andino [albazo] & Mexico \\
5. Quiaqueñita & canción [carnavalito] & Ecuador \\
6. La Petenera & son huasteco & Argentina \\
7. Quebrada de Humahuaca & folklore quechua y aymará [carnavalito] & Mexico \\
8. Así como hoy matan negros & [nueva canción] & Chile \\
9. La mariposa & morenada boliviana & Bolivia \\
10. Flor de Sancayo & huayno peruano & Peru \\
11. Fiesta puneña & bailecito & Argentina \\
\hline
\end{tabular}

Figura 1. Listado de temas musicales del LP de Inti-Illimani de 1970 Cóndores del Sol (EMI LDC-35254). El género descrito en las notas interiores aparece primero (cuando ha sido proporcionado), seguido de la precisión del autor entre paréntesis.

centro se encontraban el cantautor santandereano Pablus Gallinazo y el dúo de hermanos Ana y Jaime, quienes más tarde habrían de alcanzar gran éxito comercial y convertirse en los más conocidos representantes de la canción protesta en Colombia. Estos artistas se anticiparon algunos años a la influyente ola musical del Cono Sur, si bien Ana y Jaime más tarde habrían de popularizar en Colombia canciones como «Ni chicha ni limoná», del icono de la nueva canción Víctor Jara, y «A desalambrar», de la figura del canto popular uruguayo, Daniel Viglietti. No obstante, para finales de la década de 1970 músicos progresistas en las ciudades andinas de Bogotá y Medellín, en especial aquellos que estudiaban en universidades públicas, ya habían sido atraídos por el tipo de música diseminada por grupos de la NCL que más tarde sería conocido como «música latinoamericana».

Durante mi exploración de materiales de archivo en Colombia, encontré que el término «canción protesta» fue reemplazado por la expresión «canción social» entre las décadas de 1980 y 1990 . Hoy, la categoría «canción social» incluye tanto a las conocidas estrellas de la NCL, como a cantantes colombianos de canción protesta de décadas anteriores y artistas contemporáneos asociados a una variedad de tendencias estéticas y políticas. Mientras que la canción social es, entonces, relativamente heterogénea en términos de estilo musical, persiste un vínculo 
firme entre la música latinoamericana y la noción de música comprometida que la canción social representa.

Antes de continuar, es preciso hacer una aclaración terminológica. El uso que aquí doy a la expresión «música latinoamericana» procura reflejar su empleo en el lenguaje corriente y la manera en que la usan mis entrevistados ${ }^{4}$. En Colombia, este apelativo es empleado de modo intercambiable con "música andina» para denotar de forma general el estilo musical descrito anteriormente, en el que ocupan un lugar central géneros folclóricos e instrumentos de los Andes centrales (Ecuador, Perú, Bolivia y los extremos septentrionales de Argentina y Chile) $)^{5}$. En algunos casos, sin embargo, la categoría «música latinoamericana» excede los límites de la música andina e incluye estilos folclóricos de otros países latinoamericanos. El significado que pretendo aquí es acaso mejor encapsulado por la expresión «música andina latinoamericana», de uso menos frecuente. Para confundir la nomenclatura aún más, el término «música andina colombiana» designa las formas musicales criollas (e.g., bambuco, pasillo) oriundas de la región andina del país. Aunque no me puedo permitir aquí una explicación detallada de los aspectos musicales que diferencian la música andina y la música andina colombiana, una importante distinción radica en que los instrumentos de viento amerindios como la quena y la zampoña son vitales en la primera, mientras que la última se fundamenta en varios instrumentos de cuerda adaptados de modelos europeos (e.g., tiple y bandola).

\section{MÚSICA LATINOAMERICANA EN COLOMBIA}

A principios de la década de 1970, un reducido número de agrupaciones empezó a interpretar música latinoamericana en Bogotá, incluyendo Los Hermanos Escamilla, quienes tenían lazos con el Partido Comunista. Pero fue tan solo durante la segunda mitad de la década que un grupo de músicos, la mayoría de

4 Este artículo se basa en investigación etnográfica y de archivo desarrollada en varias ciudades del interior de Colombia entre 2011 y 2014.

5 Por ejemplo, nótese cómo el músico citado en la página 301 alterna entre ambas expresiones. Pese a la dificultad que implica establecer con precisión cómo fue que el término «música latinoamericana» llegó a referirse a este formato específico en Colombia, es claro que la denominación ya estaba en uso a principios de la década de 1980. La expresión parece haber tomado un significado similar en Perú (Oliart y Lloréns, 1984, p. 81) y Chile (Laura Jordán, comunicación personal). Debe insistirse en que el término no acarrea el mismo significado en toda Latinoamérica: en Bolivia este tipo de música fue llamada música nacional pues, en efecto, buena parte de ella se basa en géneros bolivianos (Ríos, 2009, p. 11). 
los cuales estudiaban en las universidades públicas de la capital, comenzaron a formar conjuntos que habrían de convertirse en los mayores exponentes del estilo en Colombia en la década de 1980, incluyendo Chimizapagua (ca. 1976), Tikchamaga (ca. 1977) y Alma de los Andes (ca. 1978). En Medellín, la segunda ciudad más poblada de Colombia, algunos miembros del Partido Comunista fundaron Quiramaní hacia 1975 y durante sus primeras intervenciones interpretaron repertorio del nuevo cancionero argentino y la nueva canción chilena en eventos organizados por el partido en la ciudad (Safira, comunicación personal). La agrupación que ha operado como principal canal para la circulación de la agenda musical establecida por los conjuntos de la NCL es Grupo Suramérica, creado por estudiantes universitarios en 1976. Músicos en la ciudad de Cali (Waxer, 2001, p. 235), el pueblo de Sevilla (Ochoa, 1996, p. 95) y la ciudad de Pasto (Broere, 1989, p. 117), en el suroccidente colombiano, también experimentaron con la música latinoamericana de la NCL durante la década de 1970.

Pero si la música latinoamericana echó raíces en Colombia durante la década de 1970, la de 1980 marcó su apogeo. En 1980 Grupo Suramérica organizó el «Concierto para Latinoamérica», un evento que reunió una docena de conjuntos especializados en el estilo de la música latinoamericana, y que atrajo a treinta mil espectadores (Londoño, 1980). Pocos meses antes de la segunda edición del evento en 1981, los titulares de uno de los periódicos más importantes de Medellín anunciaron: «La música latinoamericana se abre paso entre los jóvenes» (1981). Otro concierto latinoamericano a gran escala tomó lugar ese mismo año en Bogotá (figura 2). Muchos de los músicos con quienes hablé recuerdan la década de 1980 como una época durante la cual ese formato musical gozó de una moda pasajera. Con la música cada vez más accesible gracias a los programas radiales especializados, así como a los festivales y las concurridas peñas en que se presentaban grupos en vivo con regularidad (Roger Díaz, comunicación personal), varias agrupaciones nacieron para satisfacer la creciente demanda, los más prominentes de los cuales fueron Vilcapampa (1979), Nuestra América (ca. 1981) e Illari (1986), todos de Medellín. Sin embargo, pocos de los primeros grupos en adoptar la música latinoamericana continuaron este tipo de trabajo durante la década de 1990. En efecto, hacia finales de la década de 1980, la corriente comprometida de la música latinoamericana empezó a ceder paso ante la tendencia convencional que abordaba temas relativos al amor romántico. El ejemplo icónico de este enfoque es el famoso grupo boliviano de música folclórica Los Kjarkas, al que varios de mis entrevistados señalaron como responsable de llevar el estilo en dirección comercial. 


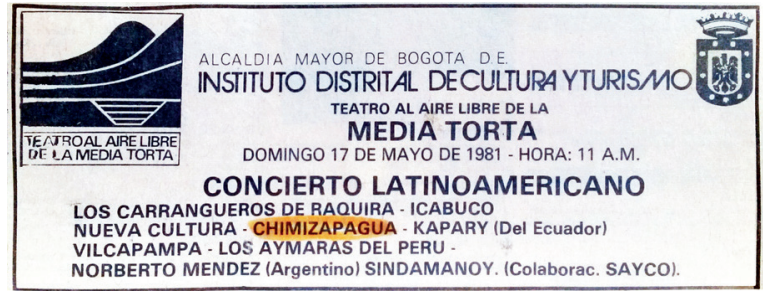

Figura 2. Volante del «Concierto Latinoamericano» que tomó lugar en Bogotá en 1981 (de la colección personal de William Morales).

\section{EL DISCURSO EN LOS PROYECTOS CULTURALES DE LA MÚSICA LATINOAMERICANA}

Como indiqué en la introducción, la descripción que hace Roy del funcionamiento de un proyecto cultural puede ser de utilidad para comprender cómo las categorías musicales adquieren significado sociopolítico: «Un proyecto cultural es una actividad coordinada por un grupo identificable de individuos para definir una categoría de objetos culturales, distinguirla de otros objetos culturales, declarar su importancia y significado, promover su adopción por parte de otros, y de ese modo producir un impacto social» $\left(2010\right.$, p. 50) (mi énfasis) ${ }^{6}$. Como se ve aquí, tres de las iniciativas interrelacionadas que confluyen en un proyecto cultural arquetípico para producir un discurso coherente sobre los objetos culturales que se encuentran en su núcleo son: «trabajo de definición» (definition work), «trabajo de delimitación» (boundary work) y «atribución de importancia» (significance claims). El análisis de las ideas acerca de la música latinoamericana que forjaron proyectos culturales sucesivos - los movimientos musicales políticamente comprometidos en el Cono Sur, en el ámbito internacional de la NCL y en Colombia - nos permite observar cómo los discursos relativos a este estilo fueron propagados y adaptados en distintos contextos geográficos y temporales.

Como demostraré más adelante, los músicos colombianos recibieron muchas de sus originales creencias extramusicales acerca de la música latinoamericana de manos del emergente complejo de la NCL, cuyos principales impulsores fueron los movimientos politizados del Cono Sur. A partir del Encuentro Internacional

6 «A cultural project is a coordinated activity by an identifiable group of people to define a category of cultural objects, distinguish it from other cultural objects, make claims about its significance and meaning, promote its adoption by others, and thereby have a social impact» (Roy, 2010, p. 50). 
de la Canción Protesta que tomó lugar en Cuba en 1967, artistas de numerosos países latinoamericanos convivieron de manera regular en el circuito de festivales de la NCL entre las décadas de 1970 y 1980. Dentro de este ámbito panlatinoamericano, músicos con filosofías políticas similares —aunque de ningún modo uniformes - fueron debatiendo las asociaciones ricamente estratificadas que en años anteriores, y dentro de sus respectivos contextos nacionales, habían atribuido a la música latinoamericana ${ }^{7}$. Como tal, la tarea de identificar en modo comprensivo los temas que prevalecen en el discurso sobre la música latinoamericana desde una perspectiva transnacional, constituye un asunto espinoso que se encuentra más allá de los objetivos de este estudio. Siguiendo el modelo de Roy, quiero enfocarme aquí en una atribución de importancia fundamental, un ejemplo de la delimitación de esta categoría musical y, finalmente, lo que propongo en términos generales como su preocupación por establecer definiciones, con el propósito de comprender cómo evolucionaron estas nociones en Colombia.

\section{UNIDAD LATINOAMERICANA / ANDINA}

Es claro que la celebración de una identidad latinoamericana unificada era uno de los atributos de valor que justificaba la adopción y proyección de la música latinoamericana por parte de los músicos de la NCL a lo largo y ancho del continente. En Argentina, un sentido de «americanidad» había guiado el trabajo de los músicos involucrados en el nuevo cancionero durante la década de 1960 (Molinero y Vila, 2014, p. 195). En Chile es posible atribuir parte de este sentimiento latinoamericanista a los compositores de la nueva canción, quienes expresaron su parentesco cultural con los demás pueblos latinoamericanos a través de las letras de las canciones y la selección de géneros musicales en los que destacaban expresiones folclóricas andinas, así como de otras regiones latinoamericanas (Orrego Salas, 1985, pp. 6-7; Rodríguez Musso, 1988, p. 62). Guillermo Barzuna cita varias canciones de músicos de la NCL de Chile, Argentina, Uruguay y Cuba que promueven la idea de la unidad continental (1977, pp. 105-114). De modo semejante, músicos afiliados a la NCL en México (Pacheco, 1994, p. 336) y Nicaragua (Scruggs, 2006) racionalizaron su compromiso con los estilos folclóricos

7 De hecho, Fernando Ríos ha demostrado que los procesos por medio de los que la música andina adquirió connotaciones políticas se desarrollaron desde un principio gracias a las redes transnacionales cosmopolitas que enlazaban Latinoamérica y Europa (2008, pp. 154-155). 
panlatinoamericanos asumiendo como premisa la necesidad de crear un frente unificado para luchar contra los regímenes despóticos que sometían el continente.

Aparentemente, aquellos músicos que adoptaron la música latinoamericana en Colombia durante la década de 1970 eran conscientes de los valores y la importancia que acarreaba la categoría. Gustavo Escamilla, miembro del conjunto Los Hermanos Escamilla, describió así la mentalidad predominante al interior de la cohorte de artistas revolucionarios de la que formaba parte: «Entonces comienzan unos textos preciosos a decir "América Latina tiene que ir de la mano pa' construir una sociedad unida". Un pensamiento latinoamericano comienza a nacer. No colombiano, ni argentino, ni chileno. Latinoamericano» (comunicación personal $)^{8}$. Es elocuente el hecho de que los nombres de grupos de música latinoamericana en Colombia, como Grupo Suramérica y Nuestra América, invocan la noción de una identidad continental. Esta idea también estuvo presente en las cubiertas de los discos y en los programas de los conciertos de dichos conjuntos a lo largo de la década de 1980, como se lee en el programa de una presentación que ofreció Chimizapagua en Bogotá en 1984, donde el grupo declara como su propósito combinar música de toda la región andina «para reafirmar la unidad latinoamericana en su expresión cultural» (Chimizapagua, 1984).

No obstante, mis hallazgos sugieren que la reivindicación de una forma de unidad cultural andina más particular surgió en Colombia como discurso para justificar la interpretación de música latinoamericana de orientación andina, en conjunto con el desarrollo de un proyecto cultural distintivo basado en la música hacia finales de la década de 1970. Su compromiso con la música ha permitido a estos músicos reafirmar los lazos culturales que existen entre Colombia en tanto nación andina, y el núcleo andino que abarca desde el noroeste de Argentina y el norte de Chile, hasta Bolivia, Perú y Ecuador. En una entrevista de 1981, por ejemplo, un miembro de Alma de los Andes aseguró: «Esta música andina que interpretamos $[\ldots]$ nos convierte en verdaderos hermanos de los argentinos del Norte, de los chilenos, bolivianos, peruanos y ecuatorianos» (Cruz Cárdenas, 1981). Los músicos que entrevisté insistieron de modo consistente en que la región montañosa del suroccidente colombiano hace parte de la región andina. A menudo respaldaban su postulado de acuerdo con el cual Colombia es parte

La primera mitad del fragmento citado parece provenir de la canción «Venas abiertas», grabada por la luminaria del nuevo cancionero argentino, Mercedes Sosa. 
del mundo andino, argumentando que la extensión del imperio inca alcanzó el extremo actual del suroccidente colombiano'.

El vínculo entre las tierras altas del sur de Colombia y el resto de los Andes sudamericanos se materializó en el trabajo de la agrupación Chimizapagua, que dividió sus presentaciones y grabaciones, más o menos de modo equitativo, entre la interpretación de música latinoamericana, y la del ensamble musical del sur de Colombia conocido como chirimía (figura 3). Muchos colombianos tienden a asociar este último tipo de ensamble, compuesto de flautas traversas y tambores, y que ha sido interpretado tradicionalmente por músicos de comunidades indígenas y campesinas, y de manera más estrecha con expresiones musicales al sur de la frontera colombiana, que con la comúnmente denominada «música andina colombiana», el tipo de música basada en cordófonos que es icónica de los Andes centrales en Colombia. En las notas del programa de uno de los conciertos que Chimizapagua ofreció en 1991, por ejemplo, el folclorista Guillermo Abadía Morales afirmaba que es posible identificar los «acentos rítmicos» de la música de las «zonas incaicas» en la música tradicional del suroccidente colombiano.

La segunda y tercera generación de intérpretes comprometidos de música latinoamericana en Colombia han seguido argumentando que comparten una identidad cultural andina profundamente enraizada. Esta insistencia es uno de los principales atributos de importancia que tiene la música andina latinoamericana. En 2011 hablé con miembros del conjunto Nuestro Tiempo, fundado en Medellín en 1999. Uno de los músicos manifestó su convicción en que ciertos géneros folclóricos del sur andino en Colombia «tienen más similitud, tienen un poco más de aire de chacarera argentina, de cueca chilena, de música ecuatoriana» (comunicación personal). Constaté la vigencia de esta idea entre personas involucradas en la música andina durante mi participación en una de las tropas de sikuris activas en el área de Bogotá. Aunque estos conjuntos se enfocan musicalmente en la interpretación de consortes de zampoñas de Perú y Bolivia, también interpretan un único tipo de música de origen nacional: la chirimía.

9 De hecho, la cohesión política de la franja de tierra bajo el control del inca ya había inspirado el enfoque conceptual de artistas de la nueva canción chilena (Ríos, 2008, p. 156). 


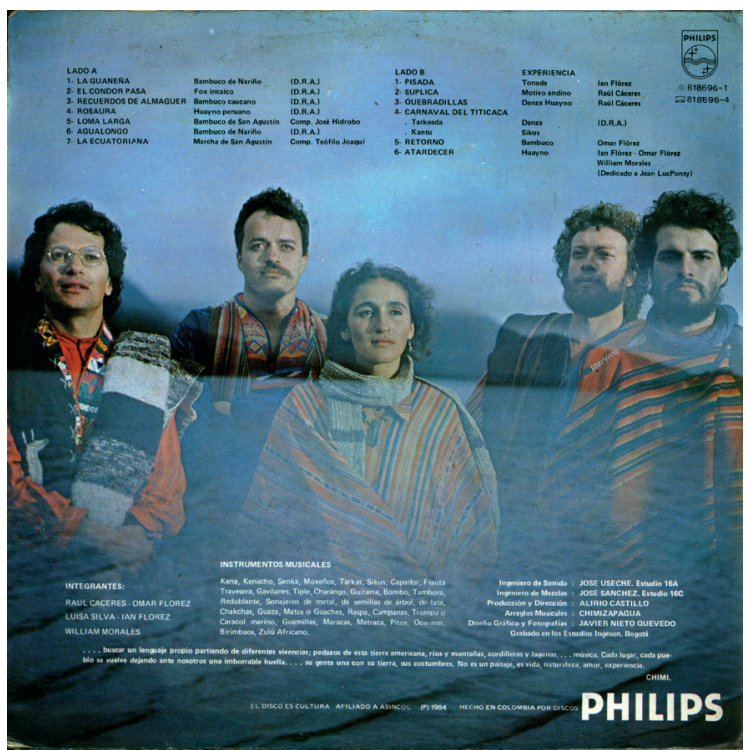

Figura 3. Contratapa del disco de Chimizapagua publicado en 1984, Experiencia (Phillips 818696-1).

\section{ANTIMERCANTILISMO}

La evocación simbólica de la unidad latinoamericana que los participantes del movimiento de la NCL atribuyeron a la música latinoamericana, estaba estrechamente emparentada con el «trabajo de delimitación»a través del que se posicionaron frente a las expresiones culturales no latinoamericanas, y por oposición a la música comercial popular ampliamente definida. En su manifiesto de 1963, los artistas que impulsaron el nuevo cancionero argentino ya habían denunciado que la música estaba siendo objeto de «la invasión de las formas decadentes y descompuestas de los híbridos foráneos» y que estaba siendo cooptada por intereses comerciales (Tejada Gómez, 2003[1963]). De manera semejante, los músicos de la nueva canción chilena, que empezaron a incorporar géneros latinoamericanos en su trabajo hacia finales de la década de 1960, estaban reaccionando de modo simultáneo al predominio de la música euroestadounidense en los medios de comunicación convencionales, y a la orientación comercial que dominaba la escena de neofolclor que había surgido al inicio de la década (Rodríguez Musso, 1988, p. 60; Torres, 1980, p. 40). Al evocar los principios que él y los demás cofundadores de Quilapayún buscaron mantener en su propio conjunto, Eduardo Carrasco Pirard escribió: 
«Nosotros no queríamos hacer concesiones a lo comercial [...] Rechazábamos también la penetración anglosajona en nuestra música [...] en esto durante mucho tiempo llevamos nuestro latinoamericanismo hasta el extremo» (2003, p. 22). Carrasco también ha propuesto el establecimiento de una estricta línea divisoria entre la canción popular común y corriente que se adscribe a los mandatos del mercado y se acomoda a la hegemonía de influencias extranjeras, y las diversas manifestaciones de la nueva canción en Latinoamérica (1982, pp. 601-602).

A principios de la década de 1980, mientras los músicos colombianos desarrollaban su propia comprensión acerca de lo que la música latinoamericana significaba, mantuvieron una distinción discursiva análoga en torno a la música. Por ejemplo, un artículo sobre Chimizapagua indica que su música constituye «un desafío a la comercialización y al gusto impuesto por las casas disqueras y las culturas foráneas» (Acero, 1982). Los músicos de Alma de los Andes aludieron de manera más específica a las formas musicales que ellos sintieron que estaban corrompiendo la identidad latinoamericana: «No desconocemos el rock, ni la música disco, ni la música country. Pero en realidad es mínimo el aporte que esas expresiones pueden darnos a nosotros, los jóvenes latinoamericanos, y en general, a la cultura de nuestro continente» (Cruz Cárdenas, 1981).

Los simpatizantes contemporáneos de la música latinoamericana parecen haber heredado la postura anticomercial forjada años atrás, pues siguen estableciendo distinciones entre la música latinoamericana comprometida, y la música popular comercial que predomina en los centros cosmopolitas de Colombia. Entre los músicos que viven en las metrópolis de los Andes centrales en Colombia, esta postura se manifiesta en los celos que les despierta la popularidad de la que goza la música latinoamericana en ciudades del suroccidente colombiano, como Pasto y Popayán. Eso sin mencionar el público masivo que disfruta este tipo de música en países andinos como Ecuador y Bolivia. Por ejemplo, una publicación en la página de Facebook de un grupo de Medellín estableció una división tajante entre un festival en Quito, Ecuador, en el que se presentarían varios de los grupos de la NCL que dieron forma al formato de música latinoamericana, y los conciertos que Madonna ofrecería en Medellín durante esas mismas fechas:

Un saludo a todos los quiteños que estas noches han gozado con las canciones que nos vieron crecer, con la canción que aún hace falta y sigue vigente, con la canción imprescindible. Quilapayún, Inti Illimani [...] qué gran deleite de buena música que no necesita de escenarios estrafalarios, ni bailarines, ni ídolos de barro creados por el mercadeo y el escándalo, como la que visitará nuestra ciudad mañana. Disfruta Quito la buena música, de esa que poca queda (27 noviembre de 2012). 
Hoy, los intérpretes de música latinoamericana perciben que el impúdico mercantilismo del reggaetón, un género de inconfundibles raíces latinoamericanas, constituye la mayor amenaza a los valores progresistas que se encuentran codificados en su medio preferido. El reggaetón mezcla hip-hop y reggae dancehall jamaicano con letras en español. Cobró enorme popularidad en toda Latinoamérica a principios del nuevo milenio, y hoy sigue siendo una tendencia vital (Marshall, 2010). Aun cuando muchas de las primeras estrellas del género y gran parte de sus consumidores iniciales eran puertorriqueños, recientemente los titulares de un periódico en Colombia pregonaron: «Medellín desbanca a Puerto Rico como “capital mundial del reguetón"» (El Tiempo, 2013, octubre 17). En reacción a esta tendencia, Roger Díaz, de Illary me dijo: «Lamentablemente es una ciudad ya absolutamente inundada por el reggaetón [...] y por un estilo de vida que cada vez es más consumista, cada vez es más clasista [...] hay algunos sectores que la ven [la canción social] como algo que [...] no vale la pena difundir». En Bogotá, un músico que durante la década de 1980 formó parte de Quinteto Fuga, un conjunto vocal de música latinoamericana, yuxtapuso de modo semejante las asociaciones simbólicas evocadas por la música latinoamericana a aquellas que acompañan el reggaetón: «El simbolismo es básicamente [...] histórico, ¿no? La música latinoamericana igual Inti Illimani, igual revolución chilena, igual barbudos, igual ruanas, hippies, entonces la gente relaciona eso. O sea, la gente no relaciona la música andina, por ejemplo, con lentes de sol, o con relojes, o con carros, como sí lo hace con el reggaetón» (comunicación personal).

\section{UNA DEFINICIÓN GENERAL}

No es sorprendente que los músicos arriba citados señalaran las potentes asociaciones entre música latinoamericana y crisis política en Chile. La historia de la música en ese país fue decisiva para la manera en que otros latinoamericanos, así como aquellos que se encuentran más allá del continente, procesaron su significado político. La música andina, en particular, fue colmada de fuertes asociaciones con la izquierda gracias a las inclinaciones políticas de algunos de sus diseminadores más destacados en Chile, como la familia Parra (Ríos, 2008, p. 156). También gracias al apoyo que sus célebres exponentes brindaron a la coalición de la Unidad Popular, liderada por Salvador Allende, durante la campaña presidencial de 1970, y durante su gobierno hasta 1973 (Fairley, 1989, p. 5). Un indicador claro del punto hasta el cual esta música fue identificada de manera inequívoca en Chile con política progresista, es la prohibición de facto — si bien 
nunca oficialmente decretada- que pesó sobre la música y los instrumentos andinos durante los primeros años de la dictadura (Jordán, 2009, pp. 81-83). Tras la caída del gobierno socialista, numerosos conjuntos de la nueva canción chilena recorrieron el mundo denunciando a Pinochet y promoviendo las causas de izquierda. Entre tanto, establecieron ante sus audiencias una conexión profunda entre música latinoamericana y política de izquierda (Ríos, 2008, p. 170).

Aunque los grupos más exitosos a la hora de atraer la atención internacional sobre las violaciones a los derechos humanos en su país fueron aquellos conformados por exiliados políticos chilenos, la década de 1970 fue testigo del destierro de disidentes argentinos y uruguayos que escapaban de las dictaduras en sus respectivos países, así como de sus esfuerzos por fomentar en ellos la oposición a los regímenes represivos (Sznajder y Roniger, 2009). Movimientos militantes a favor de la democracia en todo el Cono Sur cautivaron la imaginación de la izquierda colombiana a mediados de la década de 1970. Organizaciones e individuos solidarios con la causa chilena mantuvieron su apoyo (Grabe, 2000, p. 69), y la prensa de izquierda reportó de cerca la situación en Chile (Ayala Diago, 2003, p. 333). Entre los sectores más radicales de la sociedad colombiana, grupos armados rebeldes crearon lazos con organizaciones guerrilleras en Argentina, Chile y Uruguay. En algunos casos, ciertos miembros colaboraron de forma directa con organizaciones guerrilleras en esos países, e incluso hubo quienes recibieron casetes de música y poesía (Grabe, 2000, pp. 69, 85, 135-137). De este modo, mientras que los primeros aficionados a la música latinoamericana en Colombia eran más propensos a asociarla con la lucha chilena, muchos de ellos definieron el estilo en modo más general como relacionado con la resistencia frente a las dictaduras en el Cono Sur. William Morales, quien antes de unirse a Chimizapagua conformó el dúo Por Latinoamérica junto a un exiliado argentino, trazó una correlación directa entre la instauración de regímenes dictatoriales en Chile y Argentina, y la recepción que tuvo la NCL a mediados de la década de 1970 entre estudiantes de la Universidad Nacional en Bogotá: «Estamos hablando de un momento álgido, de las problemáticas políticas de Argentina; estamos hablando de las políticas problemáticas de Chile. Nosotros éramos un conglomerado estudiantil que recibía esas influencias. Estamos hablando de Violeta Parra, de Víctor Jara, e inclusive de Atahualpa Yupanqui» (comunicación personal).

En un festival de canción latinoamericana organizado en 1976 en Bogotá, que llevó por nombre «Este canto en libertad», y del cual formar parte artistas de varios países, los participantes leyeron un «manifiesto de solidaridad con las víctimas de la represión en América Latina» mientras un músico rasgaba un charango en el 
fondo («Este canto en libertad», 1976). Aunque no cabe duda que la declaración incluía denuncias de las violentas tácticas usadas para aplastar a las disidencias políticas en las naciones del Cono Sur, el movimiento panlatinoamericano de la NCL se ocupaba de la opresión estatal, la revolución socialista/comunista y el antimperialismo en todo el continente y más allá (e.g., la guerra de Vietnam). A finales de la década de 1970, esfuerzos revolucionarios como los que tomaron lugar en Centroamérica atrajeron la atención internacional, por lo que numerosos conjuntos de la nueva canción, conformados por exiliados políticos que interpretaban el formato de música latinoamericana, invocaron a través de su trabajo la solidaridad con los combatientes revolucionarios y los pueblos que se proponían liberar (Fairley, 1989, p. 14). En un nivel básico, entonces, los músicos y activistas de la NCL posicionaron la música latinoamericana durante la década de 1970 como expresión fundamental de las aspiraciones contrahegemónicas de la comunidad latinoamericana de izquierda (Bodiford, 2007).

Durante el auge de la música latinoamericana en Colombia en la década de 1980, sin embargo, algunos músicos especializados en este estilo trataron de distanciarse de asociaciones políticas. Refiriéndose a los orígenes del conjunto Nuestra América, a principios de la década de 1980, un miembro comentó: «Se estaba saliendo de la época de la música protesta y desde un principio se comenzó a trabajar un mensaje que se saliera del panfleto político] («Notas para un continente», 1993). Pese a que no me es posible aquí explorar las motivaciones tras este aparente cambio, es preciso notar que el fin de la década de 1970 marcó el inicio de un período de intensa represión política en Colombia. En 1978 el presidente Julio César Turbay Ayala impuso un estatuto de seguridad destinado a reprimir la actividad política de izquierda, e instauró estrictos controles a la prensa y los medios de comunicación (Palacios, 2006, p. 197). Más de un músico me dijo haber sido víctima de la censura y las amenazas del establecimiento, tanto de forma directa como indirecta, durante este tiempo. Por otro lado, la principal audiencia de música latinoamericana durante la década de 1980, y la fuente de donde provenían muchos de sus intérpretes, era la población estudiantil, que desde la década de 1960 estaba cada vez más identificada con la izquierda, y que a principios de la década de 1980 venía incrementando sus actividades de protesta en diversos frentes (Archila Neira, 2003, pp. 150, 398). Muchos de mis entrevistados coincidieron en afirmar que este grupo demográfico contribuyó a perpetuar las connotaciones políticas generales de la música en el dominio público.

Es evidente que los practicantes contemporáneos de música latinoamericana deben negociar las múltiples — y a veces contradictorias — capas de simbolismo 
que esta ha acumulado a través de las décadas desde que echó raíces en Colombia. Los músicos-activistas del conjunto Nuestro Tiempo, por ejemplo, deploraron que la música latinoamericana se hubiera puesto de moda en Medellín durante la década de 1990, hecho al que atribuyeron que esta perdiera parte importante de su trascendencia política. Uno de los miembros confesó haber tocado durante una breve temporada en un conjunto conformado con base al modelo de Los Kjarkas, y dijo haberse sentido profundamente escindido entre la orientación predominantemente romántica del repertorio de esta agrupación, y las realidades de violencia y pobreza que experimentaba en su barrio obrero. Incluso si reflexionan de modo crítico acerca de su distancia cultural respecto a la era de fervor revolucionario en que la música latinoamericana fue introducida en Colombia, los miembros de Nuestro Tiempo buscan recuperar parte de la resonancia política que este tipo de música acarreaba originalmente. Por ejemplo, cuando pregunté por qué seguían acometiendo su proyecto de compromiso político fundamentalmente a través del formato de música latinoamericana, un miembro respondió:

De pronto hay un poco de terquedad. Si bien lo que te estamos describiendo es la tendencia contraria, que hay una ruptura como con esas formas, de ese cancionero antiguo, y la canción contestataria $[. .$.$] el grupo en un principio$ $[\ldots]$ no se llamaba Nuestro Tiempo, tuvo otros nombres, [pero nosotros tuvimos que] patinar en esa contradicción [porque] bueno es que ya es un cliché, bueno es que ya eso era de los setenta, entonces la gente decía: «hombre, es que hablar de música política y desde la zampoña al charango, el cuento tan quemado», y toda la vaina. Y quizás fue romántica la posición, pero por eso dijimos: «Es Nuestro Tiempo», como para reservarnos el derecho de cantar desde ese formato, porque tiene un sentido. Ese formato es construido muy eclécticamente, pero es un rompecabezas que une a Latinoamérica en un escenario; una apuesta en escena [...] Y eso tiene una intención política ya $[\ldots]$ Tienen un sentido los ponchos, tienen un sentido las quenas, las zampoñas, todo eso.

Pese a la aparente «ruptura» entre la música latinoamericana y las interpretaciones políticas dominantes forjadas para ella a lo largo de la década de 1970, el «trabajo de definición» desarrollado en el contexto de la NCL aseguró que, en lenguaje común en Colombia, se estableciera una ecuación duradera entre el núcleo andino del estilo musical y las tendencias políticas antisistémicas. Tuve la oportunidad de observar un ejemplo de esta relación cuando asistí a un consejo público sobre trabajo y derechos territoriales, convocado por una coalición de organizaciones sindicales y activistas, en la región de los Llanos orientales. No cabe duda de que la música tradicional de mayor prominencia en esta región 
es la música llanera, que típicamente se interpreta con arpa, cuatro (guitarra de cuatro cuerdas) y maracas, y que es sustancialmente distinta de la música andina. De manera sorprendente, los únicos instrumentos que vi en la reunión fueron quenas y zampoñas andinas. Más aún, la música latinoamericana figuraba de modo conspicuo en la ambientación musical previa y posterior al consejo. Pero las asociaciones indelebles entre música latinoamericana e izquierdismo también tienen su lado oscuro: en un estudio sobre el violento conflicto armado en el norte de Colombia, una informante describió cómo los paramilitares la acusaron de estar vinculada con la guerrilla de las Fuerzas Armadas Revolucionarias de Colombia (FARC) — una acusación que conlleva el mayor peligro - tan solo porque ella escuchaba música andina (Madariaga, 2006, p. 52).

En virtud del persistente simbolismo político unido a la música latinoamericana, resulta natural que este estilo siga estando vinculado con la categoría general con que suele clasificarse la música comprometida, es decir, la denominada «canción social». Un ejemplo de esta asociación ocurrió en el centro de Bogotá, cuando pregunté a un vendedor ambulante si tenía discos de música folclórica andina y respondió que en cambio tenía LP de canción social. La manera en que la audiencia superpone ambas categorías no es ajena a los funcionarios de la división de mercadotecnia de la industria musical, como demuestra el anuncio publicitario que acompaña el CD Canción Social: grandes clásicos vol. 2, en el que se enumeran las grabaciones producidas por el sello dentro de la categoría de «Música Andina y Canción Social» (varios artistas, 2002). De hecho, cuando a principios del nuevo milenio los sellos colombianos independientes trataron de capitalizar el interés de su audiencia en compilaciones de canción social, acudieron a conjuntos especializados en música latinoamericana para que grabaran sus propias versiones de las piezas esenciales de ese repertorio. Por tanto, los escenarios en que se suelen interpretar canción social y música latinoamericana tienden a coincidir. Los grupos dedicados a la música latinoamericana usualmente son incluidos en eventos que llevan el rótulo de «canción social», como cuando en 2009 el Grupo Suramérica encabezó el «Primer Festival de la Canción Social 1 en Medellín. De manera inversa, los festivales de música andina típicamente presentan al menos un conjunto que puede ser categorizado principalmente bajo la rúbrica de «canción social». En otros casos, la correspondencia entre estas categorías es explícita, como en la «Noche de Canción Social, Andina y Latinoamericana» que tuvo lugar en Medellín en 2012 (figura 4). 


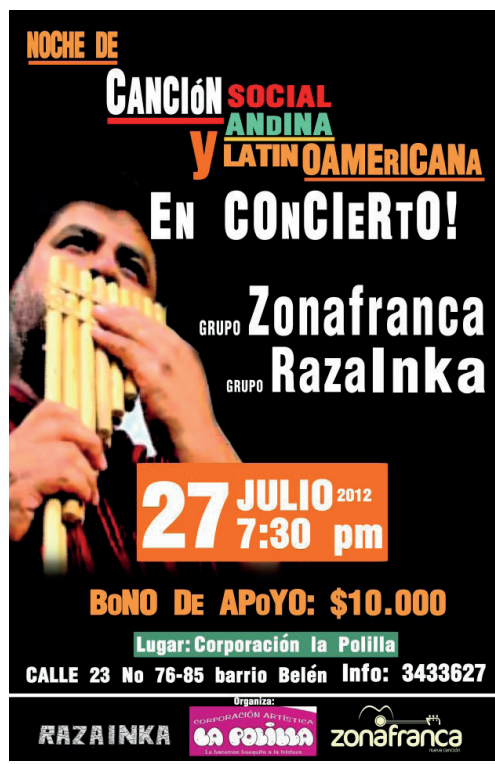

Figura 4. Afiche promocional del concierto «Noche de canción social andina y latinoamericana».

\section{CONCLUSIONES}

Durante la década de 1970, los conjuntos de la NCL inspiraron a músicos de izquierda en Colombia a cultivar la música andina latinoamericana. Ideas relativas a la importancia, el establecimiento de límites y la definición general de las prácticas musicales en esta categoría de música folclórica de orientación andina acompañaron su llegada a Colombia. En esta coyuntura, los lazos entre la música y las luchas antidictatoriales en toda Latinoamérica por lo general eran consistentes con los significados generados para ella en el movimiento de la NCL. A medida que un proyecto cultural robusto para la música latinoamericana fue consolidándose en Colombia hacia finales de la década de 1970 e inicios de la de 1980, sus participantes reconfiguraron ciertos aspectos de este discurso. Para ellos, la interpretación de la música guardaba estrecha relación con la proclamación de lazos culturales específicamente panandinos, una idea que aún hoy es expresada de modo recurrente. Los adherentes colombianos han seguido evocando la temprana distinción entre música latinoamericana y tendencias comerciales de música popular, pero en el siglo XXI las han presentado como antídoto especial para el mercantilismo del reggaetón. Aunque algunos artistas trataron de atenuar 
las asociaciones políticas de la música latinoamericana durante la década de 1980, generaciones posteriores de músicos con vocación política han planteado la necesidad de resucitarlas. Este estilo musical aún acarrea el peculiar matiz de la política de izquierda en Colombia, y se encuentra inextricablemente unido a la categoría de «canción social».

\section{REFERENCIAS BIBLIOGRÁFICAS}

Acero, Mariela (1982, diciembre 20). Los Chimizapagua: «No hacemos folclor, lo proyectamos». Vanguardia Liberal.

Archila Neira, Mauricio (2003). Idas y venidas, vueltas y revueltas: protestas sociales en Colombia, 1958-1990. Bogotá: Instituto Colombiano de Antropología e Historia.

Ayala Diago, César (2003). Colombia en la década de los años setenta del siglo XX. Anuario Colombiano de Historia Social y de la Cultura, 30, 319-338.

Barzuna, Guillermo (1997). Cantores que reflexionan: las nuevas trovas en América Latina, San José: Editorial de la Universidad de Costa Rica.

Bodiford, James (2007). Imagining «El Pueblo»: Pan-Latin American Subaltern Solidarity and the Music of Nueva Canción (tesis de maestría). Michigan State University.

Broere, Bernard (1989). El Chambú: A Study of Popular Musics in Nariño, South Colombia (1983). En Simon Frith (ed.), World Music, Politics and Social Change (pp. 103-121). Manchester y New York: Manchester University Press.

Canciones de protesta y esperanza (1968, abril 25). Voz Proletaria, p. 2.

Carrasco Pirard, Eduardo (2003). Quilapayún: la revolución y las estrellas. Santiago: RIL.

Carrasco Pirard, Eduardo (1982). The Nueva Canción in Latin America. International Social Science Journal, 94(4), 599-623.

Chimizapagua (1984, octubre 5). El grupo musical «Chimizapagua». Teatro Colsubsidio Roberto Arias Pérez.

Cruz Cárdenas, Antonio (1981, marzo 13). En la onda de la música andina. Carrusel, 10-11.

Este canto en libertad: éxito total (1976, agosto 30). Alternativa, 18.

Fairley, Jan (1989). Analysing Performance: Narrative and Ideology in Concerts by ¡Karaxú! Popular Music, 8(1), 1-30. 
Gómez, Alejandro (1973). Con Alejandro Gómez. Boletín Música Casa de las Américas, 42, s.p.

Grabe, Vera (2000). Razones de vida. Bogotá: Planeta.

Jordán, Laura (2009). Música y clandestinidad en dictadura: la represión, la circulación de músicas de resistencia y el casete clandestino. Revista Musical Chilena, 63(212), 77-102.

La música latinoamericana se abre paso entre los jóvenes (1981, marzo 27). El Colombiano, $\mathrm{C} 1$.

Londoño, Luz Marina (1980, julio 27). El público demostró avidez de cultura. El Mundo, 16-17.

Madariaga, Patricia (2006). Matan y matan y uno sigue ahí: control paramilitar y vida cotidiana en un pueblo de Urabá. Bogotá: Uniandes.

Marshall, Wayne (2010). Reggaeton. En Grove Music Online. Recuperado de https:// doi.org/10.1093/gmo/9781561592630.article.A2087540

Molinero, Carlos y Pablo Vila (2014). A Brief History of the Militant Song Movement in Argentina. En Pablo Vila (ed.), The Militant Song Movement in Latin America, Chile, Uruguay, and Argentina (pp. 193-227). Lanham, MD: Lexington Books.

Notas para un continente (1993, julio 19). El Mundo, sección Vida!, s.p.

Ochoa, Ana María (1996). Plotting Musical Territories: Three Studies in Processes of Recontextualization of Musical Folklore in the Andean Region of Colombia (tesis doctoral). Indiana University.

Oliart, Patricia y José Lloréns (1984). La Nueva Canción en el Perú. Comunicación y Cultura, 12, 73-82.

Orrego Salas, Juan (1985). Espíritu y contenido formal de su música en la nueva canción chilena. Literatura Chilena en el Exilio, 9(3-4), 5-13.

Pacheco, Javier (1994). History, Identity, and the New Song Movement in Mexico City: A Study in Urban Ethnomusicology (tesis doctoral). University of California at Los Ángeles.

Palacios, Marco (2006). Between Legitimacy and Violence: A History of Colombia, 1875-2002. Durham: Duke University Press.

Ríos, Fernando (2009). Andean Music, the Left, and Pan-Latin Americanism: The Early History. Diagonal: Journal of the Center for Iberian and Latin American Music, $2,1-13$.

Ríos, Fernando (2008). La Flûte Indienne: The Early History of Andean Folkloric-Popular Music in France and its Impact on Nueva Canción. Latin American Music Review, 29(2), 145-189. 
Rodŕguez Musso, Osvaldo (1988). La nueva canción chilena: continuidad y reflejo. La Habana: Casa de las Américas.

Roy, William (2010). Reds, Whites, and Blues: Social Movements, Folk Music, and Race in the United States. Princeton: Princeton University Press.

Sánchez, Óscar Andrés (2013, octubre 17). Medellín desbanca a Puerto Rico como «capital mundial del reguetón». El Tiempo. Recuperado de www.eltiempo.com/ archivo/documento/CMS-13128675

Scruggs, T.M. (2006). Música y el legado de la violencia a finales del siglo XX en Centro América. TRANS-Transcultural Music Review, 10, artículo 3.

Sznajder, Mario y Luis Roniger (2009). The Politics of Exile in Latin America. New York: Cambridge University Press.

Tejada Gómez, Armando (2003). Manifiesto del nuevo cancionero. En Centro Cultural Armando Tejada Gómez. Recuperado de https://web.archive.org/ web/20040625181003/http://www.tejadagomez.com.ar/adhesiones/manifiesto. html

Torres, Rodrigo (1980). Perfil de la creación musical en la nueva canción chilena desde sus orígenes hasta 1973. Santiago: CENECA.

Varios artistas (2002). Canción social: grandes clásicos, vol. 2 [CD]. Medellín: Colmúsica.

Waxer, Lise (2001). Las caleñas son como las flores: The Rise of all-Women Salsa Bands in Cali, Colombia. Ethnomusicology, 45(2), 228-259. 